season to areas of milder climates in order to ensure year-round supply of the familiar produce. Nowadays, consumers in Europe, Japan, and the United States have almost forgotten the scant vegetable displays of earlier winters. Indeed, the consumer markets in the Persian Gulf, Hong Kong, Singapore, and even Beijing now enjoy steady supplies of fresh vegetables throughout all four seasons.

From the point of view of the vegetable seed industry, global horticulture creates a major challenge: varietal adaptation. The consumers expect the same type and the same quality of produce, regardless of where it was grown. Therefore, plant breeders must try to reconcile the phenotypic requirements of the marketplace and the climatic and agronomic conditions of the new growing areas.

However, commercial varieties often are restricted in their climatic adaptation. In fact, the trend in many commercial research programs is to breed for increasingly narrow market segments and increasingly sophisticated growing practices. Even when substantial "aggregate markets" exist, seed companies are often unwilling to service these fragmented markets.

Therearefour main solutions to this problem:

1) Certain horticultural seed companies and vegetable processors with international activities have succeeded in selecting strains of commercial varieties for adaptation to new growing areas. In some cases, completely new cultivars have been developed to meet the requirements of long-distance transportation or heavy disease pressure.

2) In many countries, local seed companies are increasingly active and successful in developing cultivars that are well-adapted to both the local growing conditions and the demands of export markets. Taiwan, Thailand, and South Africa are three such examples.

3) Local horticultural research centers play a crucial role in selecting and breeding cultivars adapted to the local growing conditions. Two prominent examples come to mind: The Asian tropical tomato was developed in the 1970s at the Asian Vegetable Research \& Development Center
(AVRDC) by Ruben Villareal and his team. No seed company had seriously ventured into this difficult area, despite the significant commercial potential. The AVRDC team sampled its many lines widely throughout tropical Asia and beyond. A number of lines have since found their way into the local markets, either in their original form or after further selection and breeding steps. Similarly, a team from the International Center for Potato (CIP) in Peru had considerablesuccess in developing highquality hybrid true potato seed varieties adapted to a number of developing countries. Breeding and development work was conducted in cooperation with local research centers in each target country. Theresulting material becameavailableto farmers several years ahead of competing commercial hybrid lines. The current initiative to develop a regional seed association for the Asia/Pacific area, sponsored by the Food and Agriculture Organization of the United Nations, will undoubtedly strengthen local efforts and help overcome many of the obstacles that still exist.

4) SeedQuest, a computerized data bank for the seed industry launched in Jan. 1992, provides another valuable tool. This data bank contains standardized descriptions of all commercial vegetable varieties available worldwide and the varietal requirements of the main vegetable seed markets. It has become a unique information hub serving a variety of purposes:

- it enables farmers and seed dealers to quickly and cost-efficiently identify and pre-select suitable cultivars, thus reducing size and cost of their variety trials;

- it enables plant breeders to quickly access all product and market information they need to accurately focus their research work and, conversely, to make surethat information about their cultivars reaches specifically the seed users who need it; and

- it provides plant breeders with a uniquely powerful tool to identify areas of breeding opportunity around the world.

\section{Intellectual Property Rights in a Global Market}

\author{
Robert J. Jondle ${ }^{1}$
}

T

his article presents a brief overview of current legal options for the protection of plants. Prior to 1930, plant research and breeding were dependent upon government funds to experiment stations. There was little or no incentive for private industry to spend money on plant research. In 1930, Congress enacted the Plant Patent Act to encourage the development of new asexually reproduced varieties. Luther Burbank and StarkBrothers Nursery were strong advocates for this Act.

Fifty years later, in 1970, the Plant Variety Protection Act (PVPA) was enacted to provide patent-likeprotection to sexually reproduced plant varieties. In 1980, the Supreme Court decided, in the Chakrabarty case, that microorganisms were patentable. In the 1985 Hibberd case, plants were held to be patentable by the Board of Patent Appeals and Interferences. Plant proprietary rights and ownership rights issues have become important issues for private industry, universities, and government, both in the United States and internationally.

There are five general legal categories of plant protection currently available in the United States:

1) trade secret law;

2) contract law;

3) plant patents for asexually reproduced plants (the 1930 Plant Patent Act);

4) PVP certificates; and

5) U.S. utility patents.

Trademarks, copyrights and design patents are additional types of intellectual property rights, but are not discussed here.

Utility patents, plant variety protection and breeders' rights, and trade secret law has been discussed previously (Jondle, 1993).

\section{Contract law}

Another type of protection often used in global markets is contract law, such as licenses, sales contracts, confidentiality agreements, and label licenses (or restrictive use labels) on seed bags. The effectiveness of a contract is dependent upon the type of contract. In addition, a contract is

Henderson \& Sturm, Omaha, Neb.

'Patent Attorney. 
only enforceable between the contracting parties, and does not provide any protection against any other parties.

\section{Licenses}

Licenses havewideapplicability in anumber of areas, including intellectual property (such as patents, plant variety protection certificates, trade secrets, know how, and show how). In all licenses, the licensee receives the right to enjoy something owned by the licensor without interference from the licensor. This transfer of rights can range from a conveyance of substantially all rights to one of severely restricted rights. A license may contain a confidentiality provision. The entire agreement should be examined to determine if it is in fact a license. Because a license is more substantive than a purchase agreement, it generally involves more negotiations between the parties, and it is thus more likely to be held enforceable when compared to the standardized "boilerplate" language of purchase agreements. Licenses are governed by state laws. A license may be of any duration agreed to by the parties, but a license of a patent may not provide for royalties after the expiration of the patent. Royalties can be collected on the license of a patent application, even if the application does not mature into a patent. In such a case, there is no limitation on the length of time during which royalties can be collected.

There are three basic types of licensesexpress, implied, or license by estoppel or acquiescence. An express license is a written or oral license between a licensor and licensee. An implied license is one that is created by the language or conduct of an intellectual property owner, unless such a license would be contrary to express agreements between the parties. A license by estoppel or acquiescence is created if $i$ ) there is an unauthorized use of the property, ii) the owner knew of such use, iii) the conduct of the owner misled the user to believe the owner had abandoned interest or acquiesced in the use, and iv) there is detrimental reliance by the user (such as the building of a new production facility) on such conduct. In this factual situation, the owner is prevented (estopped) by the courts from asserting infringement of his rights on the basis of the lack of a license.

The grant of a license may be exclusive, nonexclusive, or restrictive. In essence, an exclusive license is an agreement that the licensor will not grant any other licenses after execution of the exclusive license. The exclusive license may be subject to previous nonexclusive licenses, however, and may preclude the licensor from practicing the licensed subject matter unless he or she has reserved the right to do so. A nonexclusive license is an agreement for the licensee to practice the subject matter, but allows the licensor to grant additional licenses as he or she desires. A restricted license is an agreement in which the right to practice the subject matter is limited. The license can be restricted in numerous areas, but thoserestrictions most common arebyi) duration, ii) type of activity or field of use, and iii) geographic area. An example of afield-of-use restriction is the license of plant germplasm for reproduction purposes only. In this instance, the plant germplasm cannot be lawfully used for breeding, producing hybrids, or the like. Clearly, a restricted license provides a licensor with maximum control of the subject matter.

One important aspect of a license is that the licensee is generally estopped from challenging the validity of licensed rights. Important exceptions to this rule are licenses that include patents. Once a patent has been held to be invalid or unenforceable, no further royalties are due. Because most licenses of patent rights also include know-how rights (i.e., a commercial embodiment of theinvention, or additional information that may benecessary to practice theinvention), it is important that the license apportion royalty payments between the two, so that royalty payments can still be collected for the license of know-how rights. It is important to address termination provisions in drafting a license, in the event that a patent does not issue or is invalidated, or a trade secret is lost.

\section{Conclusion}

The effectiveness of protection for each of the five general legal categories for plant protection continues to evolve and change. For example, thereis an amendment currently proposed to Congress that, if adopted, would narrow the crop or farmers' exemption for the Plant Variety Protection Act. Changes often occur when new situations and fact patterns are litigated in court. The 1987 Pioneer $v$. Holden's decision expanded trade secret law to include the genetic code of proprietary inbreds.

Some companies and universities are using combinations of thesemajor legal categories, such as contracts combined with PVP certificates; licenses combined with utility patents; applications for both PVP and utility patent protection; and trade secret protection combined with licensing. It is important to realize that different combinations of these legal categories can result in different levels of protection, and to keep informed of the evolving plant proprietary rights issues.

\section{Literature Cited}

Jondle, R.J. 1993. Legal protection for intellectual property. HortTechnology 3(3):301-307.

\section{Strategic Management in Floriculture}

\author{
William H. Carlson
}

T

here are an estimated 10,000 greenhouse operations in the United States, 6000 of which produce less than $\$ 100,000$ per year. Sixty percent of the operations produce only $9 \%$ of the total floriculture product (USDA, 1992). Less than $1 \%$ have a strategic plan. Lack of planning and poor financial management have forced many operators to sell crops below actual production cost.

There are four phases in the evolution of formal strategic planning. The first involves basic financial planning, including development of operational controls by implementing an annual budget and focusing on functional aspects of the business. Phase two is forecast-based planning, in which there is more-effective growth design. Thecompany conducts an environmental analysis and multi-year forecasts and continues static allocation of resources. Phase three consists of externally oriented planning, during which the company becomes increasingly responsive to markets and competition through careful analysis, evaluates strategic alternatives, and begins dynamic allocation of resources. Phase four includes "creating the future," or timely management to orchestrateresources and create competitiveadvantages. There is a deliberate planning framework; a creative, flexible planning process, and a supportive value system and climate (Gluck et al., 1980).

From 1986 to 1991, 10 greenhouse operations were selected to pilot the development of strategic plans: seven in Michigan, onein Canada, onein Oregon, and onein New York. Thesize of the operations varied. One grossed under $\$ 500,000$; two in Michigan between $\$ 500,000$ and $\$ 1$ million; three between $\$ 1$ million and $\$ 2$ million; two between $\$ 2$ million and \$3 million; and two more than $\$ 5$ million. Of all 10 operations, six used quarterly or semi-annual financial statements, three used monthly statements, and one used monthly financial statements and actual cost-of-production figures. However, none incorporated a formal strategic business plan.

It is interesting to note that $50 \%$ of the growers did not have a yearly budget. For one of the businesses, after developing a budget and determining expenditures during production for

Department of Horticulture, Michigan State University, East Lansing, MI 48824. 